Tropical Journal of Pharmaceutical Research October 2019; 18 (10): 2203-2209

ISSN: 1596-5996 (print); 1596-9827 (electronic)

(1) Pharmacotherapy Group, Faculty of Pharmacy, University of Benin, Benin City, 300001 Nigeria.

\title{
Analgesic use for carbon monoxide poisoning induced headache: A randomized, controlled, double-blind, clinical trial
}

\author{
Abdullah Osman Kocak ${ }^{1 *}$, İlker Akbas ${ }^{2}$ \\ ${ }^{1}$ Department of Emergency Medicine, Faculty of Medicine, Ataturk University, Erzurum, ${ }^{2}$ Department of Emergency Medicine, \\ Bingöl State Hospital, Bingöli, Turkey \\ *For correspondence: Email: abdullahmrym86@gmail.com; Tel: 0090-5445667158; Fax: 0090-4422363133 \\ Sent for review: 20 February 2019 \\ Revised accepted: 19 September 2019
}

\begin{abstract}
Purpose: To compare the effectiveness of three analgesics versus placebo in the relief of carbon monoxide (CO)-induced headache in patients with $\mathrm{CO}$ intoxication.

Methods: This study was a prospective, randomized, double-blind and placebo-controlled trial. Patients diagnosed with $\mathrm{CO}$ intoxication and who had headaches were included in the study. They were divided into four groups. Patients in group 1 received $50 \mathrm{mg}$ dexketoprofen i.v. in $100 \mathrm{~mL}$ of saline, while those in group 2 received $800 \mathrm{mg}$ ibuprofen i.v. Patients in group 3 were given I g paracetamol i.v. Group 4 patients received placebo (100 mL of physiological saline. Visual analogue scale (VAS) values were recorded at onset of treatment, and subsequently at 30th, 60th, 90th and 240th min. Patients who scored 3 and below in VAS 240 were considered to have responded to treatment.

Results: A total of 168 patients completed the study. Two analgesics and placebo significantly reduced VAS 240 score $(p<0.05)$. However, VAS 30, VAS 60 and VAS 240 values decreased significantly in the ibuprofen group, when compared to other groups $(p<0.05)$. Evaluation of response to treatment revealed no significant differences amongst the groups $(p=0.313)$.

Conclusion: These results suggest that analgesics are not superior to oxygen therapy in the treatment of headaches caused by $\mathrm{CO}$ poisoning. However, ibuprofen + oxygen treatment may be applied in people who cannot tolerate headaches for a long time.
\end{abstract}

Keywords: Analgesic, Carbon monoxide poisoning, Headache, Emergency

\begin{abstract}
This is an Open Access article that uses a fund-ing model which does not charge readers or their institutions for access and distributed under the terms of the Creative Commons Attribution License (http://creativecommons.org/licenses/by/4.0) and the Budapest Open Access Initiative (http://www.budapestopenaccessinitiative.org/read), which permit unrestricted use, distribution, and reproduction in any medium, provided the original work is properly credited.

Tropical Journal of Pharmaceutical Research is indexed by Science Citation Index (SciSearch), Scopus, International Pharmaceutical Abstract, Chemical Abstracts, Embase, Index Copernicus, EBSCO, African Index Medicus, JournalSeek, Journal Citation Reports/Science Edition, Directory of Open Access Journals (DOAJ), African Journal Online, Bioline International, Open-J-Gate and Pharmacy Abstracts
\end{abstract}

\section{INTRODUCTION}

Carbon monoxide (CO) is a colorless, odorless and non-irritant gas that is released from incomplete combustion of carbon compounds [1]. Carbon monoxide poisoning is still a major cause of morbidity and mortality in the world. Every year, hundreds of people die from CO poisoning, especially in the autumn and winter months [2]. According to forensic medicine sources in Turkey, $100-150$ people lose their lives yearly as a result of $\mathrm{CO}$ poisoning [3]. The fact that nonfire-related $\mathrm{CO}$ poisoning is responsible for 50,000 emergency service admission and 1,200 deaths per year in the United States of America 
makes it one of the main causes of intoxicationrelated deaths [4].

The clinical severity of $\mathrm{CO}$ poisoning is an index of the duration of exposure to $\mathrm{CO}$ and its intensity in the environment. It is also an index of the amount of inhaled air, and the individual's health status. Symptoms of $\mathrm{CO}$ poisoning are not unique, and so can be confused with symptoms of other diseases [5]. However, CO poisoning results in headache, nausea, vomiting and visual impairment, and death usually occurs due to respiratory arrest. One of the most common symptoms is headache, which occurs in 80 to 90 $\%$ of the cases [6]. The magnitude of the headache varies considerably amongst patients [7]. The basis of treatment in $\mathrm{CO}$ poisoning is to minimize further damage by removing the patient from the $\mathrm{CO}$ environment [8].

Since tissue hypoxia is the main problem of $\mathrm{CO}$ poisoning, the natural antidote is oxygen, based on chemical and pathophysiological data. Therefore, the patient should be given $100 \%$ oxygen with a non-breathable mask back [9]. In addition to oxygen therapy for $\mathrm{CO}$ poisoning, analgesic drugs are used to relieve headache associated with the condition. However, there is a dearth of research information on the use of analgesic in $\mathrm{CO}$ poisoning. Therefore, to prevent unnecessary drug use, studies are needed to show whether the use of analgesics for COintoxicated patients is actually beneficial. In this study, an attempt was made to compare the pain-relieving effectiveness of three analgesics in CO-intoxicated patients with headache.

\section{METHODS}

\section{Study design and setting}

This was a prospective, randomized, doubleblind and placebo-controlled trial. All patients were informed about the study and its procedures, and written informed consents were obtained from volunteers before their inclusion in the study.

\section{Inclusion and exclusion criteria}

The study was conducted in accordance with good clinical practice standards at the Emergency Department of Faculty of Medicine, Ataturk University, between November 01, 2017 and April 30, 2018. Patients diagnosed with $\mathrm{CO}$ poisoning in the Emergency Department, who had headaches were included in the study. For the treatment of $\mathrm{CO}$ poisoning, all patients were given oxygen until they were discharged (10 $\mathrm{L} / \mathrm{min}$ with mask). The patients were divided into four groups: Group 1 received dexketoprofen; group 2 was given ibuprofen, group 3 received paracetamol, while group 4 was given physiological saline (placebo).

The excluded patients were those with chronic illnesses involving the liver and kidney, those taking medications which increase the risk of bleeding, pregnant patients, patients with cognitive impairments or psychiatric disorders, and patients who used oral NSAIDs $6 \mathrm{~h}$ prior to the study. Other excluded categories were patients with history of gastrointestinal bleeding, cancer patients, patients with primary headache syndrome and brain trauma, as well as those receiving hyperbaric oxygen therapy and patients with brain ischemia due to $\mathrm{CO}$ exposure.

\section{Ethical consideration}

Ethical approval was obtained from the Ethics Committee of Atatürk University Medical Faculty Clinical Research (approval no. B.30.2.ATA.0.01.00/76). The Ethics Committee operates in line with the International Ethical Guidelines for Health-Related Research Involving Humans [10].

\section{Patients and treatments}

Clinical findings and laboratory values of $\mathrm{CO}$ poisoning were evaluated together. A sample of arterial or venous blood gas was used to diagnose $\mathrm{CO}$ poisoning. Carboxyhemoglobin $(\mathrm{COHb})$ was measured. For smokers and nonsmokers, COHb levels $>8 \mathrm{mg} / \mathrm{dL}$ and $>5 \mathrm{mg} / \mathrm{dL}$, respectively showed positive diagnosis of $\mathrm{CO}$ intoxication. After the emergency physician had obtained the patient's history and carried out physical examination, blood was taken for $\mathrm{COHb}$ measurement.

For all patients, COHb levels were measured within $10 \mathrm{~min}$ of arrival to the emergency room. Initial $\mathrm{COHb}$ levels were measured within $1 \mathrm{~h}$ after removal of the patients from the COcontaining environment. The level of $\mathrm{COHb}$ was measured in arterial or venous blood using a Cobasb 221 Blood Gas System (Roche Diagnostics, Inc, Indianapolis). Visual analogue scale (VAS) scores for headache were recorded for all patients who were included in the study. Patients were given either $50 \mathrm{mg}$ dexketoprofen i.v. in $100 \mathrm{~mL}$ of saline i.v., $800 \mathrm{mg}$ ibuprofen i.v., $1 \mathrm{~g}$ paracetamol i.v. or placebo i.v. $(100 \mathrm{~mL}$ physiological saline) for 5 min. The medication were packaged in such a way that they were not distinguishable from the outside before they were given. Pre-study, physicians and nurses were trained on the research. A web-based, computer- 
based randomization model was used to determine the patients to be included in each group.

Patients were grouped randomly and sequentially. Gender was not taken into account during the randomization, since it is not known to have any effect on the response of patients to treatment. Patients who participated in the study were treated according to the prepared randomization table. For each patient number, closed envelopes indicating which treatment the patient would receive were prepared by a physician who was naïve to the study. Similarly, the drugs to be given were prepared and packaged by a physician who was not privy to the study in advance. During the study, patients were not given any medication other than rescue therapy. The recovery drugs were planned for $240 \mathrm{~min}$, but 240 min was not expected for patients in need of analgesics during this time. The choice of the rescue drug was left to the physician's decision. All patients who started the study completed it.

\section{Parameters evaluated}

Age, sex, vital signs (blood pressure, pulse rate, respiratory rate, body temperature, and oxygen saturation) of the included patients were recorded. The VAS values were also recorded as follows: Pain at the time of admission to the hospital was taken as VAS 0 , and the VAS values measured 30, 60, 90 and 240 min after the treatment were taken as VAS30, VAS 60, VAS 90 and VAS 240. Patients who scored 3 and below in VAS 240 were considered to have responded to treatment, while those with pain score of 4 and above in VAS 240 were considered not to have responded to treatment. The need for life saving medication among patients will be assessed and recorded also.

\section{Treatment objective/outcome}

The endpoint of this study was the VAS pain score at the $240^{\text {th }}$ min of the treatment groups. In this way, the advantages of these 4 treatment options would become clearer. A comparison of the VAS 240 pain score among the groups was done to determine the effectiveness of the different analgesics.

\section{VAS evaluation for headache}

The visual analogue scale (VAS) is a safe, easy, descriptive, proven and accepted scale used for pain assessment. It consists of a $10-\mathrm{cm}$ long line which starts with "no pain" and ends with 'unbearable pain'. The patient usually has two endpoints and is free to mark any place that fits the severity of the pain between these points. Accordingly, VAS score of "0" indicates that there is no pain; scores of 1- 4 indicate mild pain, scores of $5-6$ mean moderate pain, while VAS scores of $7-10$ imply severe pain.

\section{Statistical analysis}

Data are expressed as mean \pm standard deviation (SD). Statistical analysis was performed using IBM SPSS statistics version 21.0. Non-parametric tests were used since the data did not conform to normal distribution. Mann Whitney U-test for 2 groups and Kruskall Wallis test for multiple groups (Bonferoni correction) were performed in this regard. Chi-square test was used for categorical data analysis. Spearman correlation test was used to determine correlation between the groups. Values of $p<$ 0.05 were considered statistically significant.

\section{RESULTS}

During the study period, 970 patients were admitted to Erzurum Ataturk University, Emergency Medicine Department as a result of CO poisoning. However, 201 of these patients did not agree to participate in the study, while 601 patients were excluded. The study was carried out with $168 \mathrm{CO}$ poisoning patients divided into four equal groups. The demographic data and vital signs of the patients are summarized in Table 1. There was no statistically significant difference amongst the 4 groups $(p>$ 0.05 ). Nausea was detected in 57 patients, emesis was seen in 11 patients, dizziness occurred in 39 patients, while other symptoms were seen in smaller number of patients.

The efficacy of the drugs used in this study, based on VAS pain scores, is shown in the following Figures: Figure 1 shows that dexketoprofen treatment significantly reduced VAS scores in patients with $\mathrm{CO}$ poisoning $(p<$ 0.05 ). Although the analgesic effects of dexketoprofen increased time-dependently, there were no statistically significant differences in VAS scores after 60, 90 and $240 \mathrm{~min}(p>0.05)$.

Figure 2 shows clear decreases in VAS score in patients with $\mathrm{CO}$ poisoning after ibuprofen treatment $(p<0.05)$. However, the VAS 60 and VAS 90 scores did not differ significantly after ibuprofen treatment $(p>0.05)$. Similarly, VAS90 and VAS 240 scores were comparable in the ibuprofen treatment $(p>0.05)$. 
Table 1: Patients' characteristics and vital findings

\begin{tabular}{|c|c|c|c|c|c|}
\hline \multirow[b]{2}{*}{ Variable } & \multicolumn{4}{|c|}{ Analgesic treatment } & \multirow[t]{2}{*}{ P-value } \\
\hline & $\begin{array}{l}\text { Dexketoprofen } \\
(n=42)\end{array}$ & $\begin{array}{l}\text { Ibuprofen } \\
(n=42)\end{array}$ & $\begin{array}{l}\text { Paracetamol } \\
(n=42)\end{array}$ & Placebo $(n=42)$ & \\
\hline $\begin{array}{l}\text { Age }^{a} \\
\text { Gender }^{p}\end{array}$ & $37.85 \pm 14.27$ & $36.69 \pm 10,57$ & $40.76 \pm 15.40$ & $35.85 \pm 13.58$ & 0.374 \\
\hline Male & $17(40.5 \%)$ & $15(35.7 \%)$ & $23(54.8 \%)$ & $13(31 \%)$ & 0.137 \\
\hline Female & $25(59.25 \%)$ & 27 (64.3\%) & 19 (45.2\%) & 29 (69\%) & \\
\hline Systolic $B P^{c}$ & $121.98 \pm 17.28$ & $122.50 \pm 15.99$ & $123.98 \pm 17.46$ & $121.64 \pm 13.48$ & 0.971 \\
\hline Diastolic $B P^{c}$ & $74.43 \pm 12.26$ & $73.69 \pm 11.30$ & $72.74 \pm 9.54$ & $74.60 \pm 13.54$ & 0.764 \\
\hline Heart Rate $^{c}$ & $81.19 \pm 14.79$ & $79.31 \pm 13.34$ & $84.05 \pm 16.58$ & $82.36 \pm 15.89$ & 0.693 \\
\hline $\begin{array}{l}\text { Respiratory } \\
\text { rate }^{c}\end{array}$ & $15.40 \pm 3.58$ & $15.98 \pm 3.21$ & $15.29 \pm 2.91$ & $15.95 \pm 3.27$ & 0.596 \\
\hline $\begin{array}{l}\text { Body } \\
\text { Temperature }\end{array}$ & $36.68 \pm 0.60$ & $36.60 \pm 0.48$ & $36.55 \pm 0.31$ & $36.50 \pm 0.30$ & 0.391 \\
\hline $\begin{array}{l}\text { Oxygen } \\
\text { Saturation }^{c}\end{array}$ & $97.43 \pm 1.94$ & $96.50 \pm 3.05$ & $96.24 \pm 4.25$ & $95.93 \pm 4.97$ & 0.520 \\
\hline
\end{tabular}

BP: blood pressure; ${ }^{a}$ Mann Whitney $U$ test was used, ${ }^{b}$ Chi-square test was used, ${ }^{c}$ Kruskall Wallis test was used; $p<0.05$

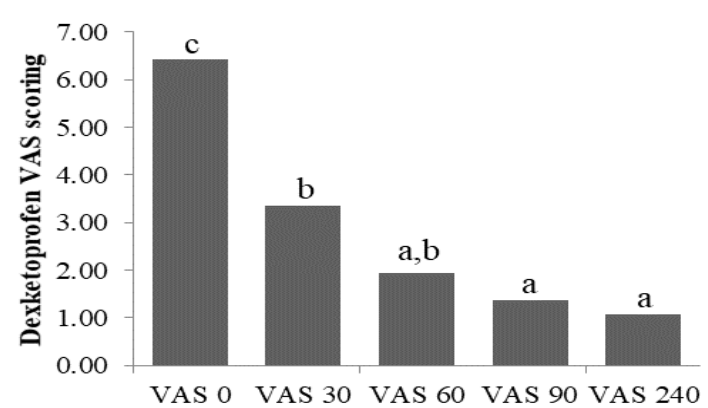

Figure 1: Effect of dexketoprofen on VAS scores in patients with $\mathrm{CO}$ poisoning. Test: Kruskall Wallis. Bars with different letters differ significantly $(p<0.05)$; bars with the same alphabets do not differ significantly. (e.g VAS 30 is significantly different from VAS 0 but VAS 30 is not significantly different from VAS 60)

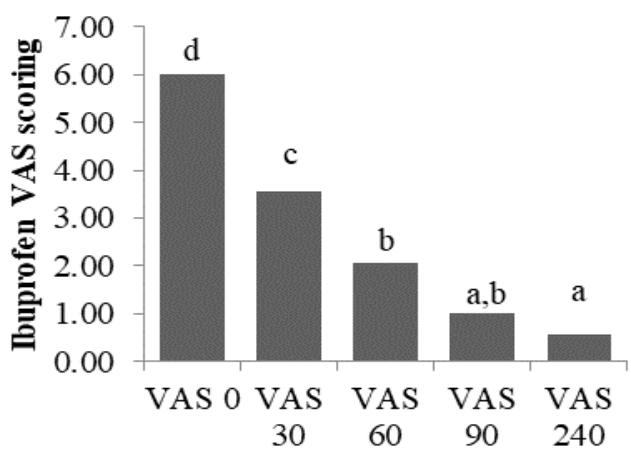

Figure 2: Effect of Ibuprofen on VAS scores in patients with $\mathrm{CO}$ poisoning. Test: Kruskall Wallis. Bars with different alphabets differ significantly $(p<0.05)$; bars with the same letters are comparable

As shown Figure 3, after paracetamol treatment, VAS scores decreased significantly with time ( $p$ $<0.05)$. However, there was no significant difference between the VAS 30 and VAS 60 scores. Moreover, VAS 90 and VAS 240 scores were comparable $(p>0.05)$.
Interestingly, placebo treatment significantly reduced the VAS scores of patients in a timedependent fashion $(p<0.05)$. However, VAS 60, VAS 90 and VAS 240 scores were comparable amongst the groups $(p>0.05)$.

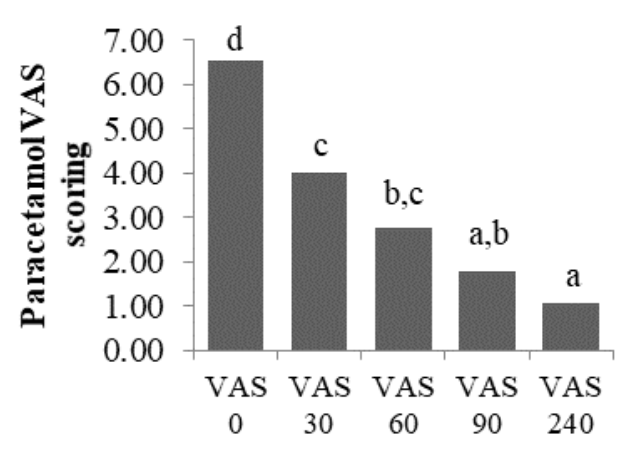

Figure 3: Effect of paracetamol on VAS scores in patients with $\mathrm{CO}$ poisoning. Test: Kruskall Wallis. Bars with different letters differ significantly $(p<0.05)$; bars with the same alphabets do not differ significantly

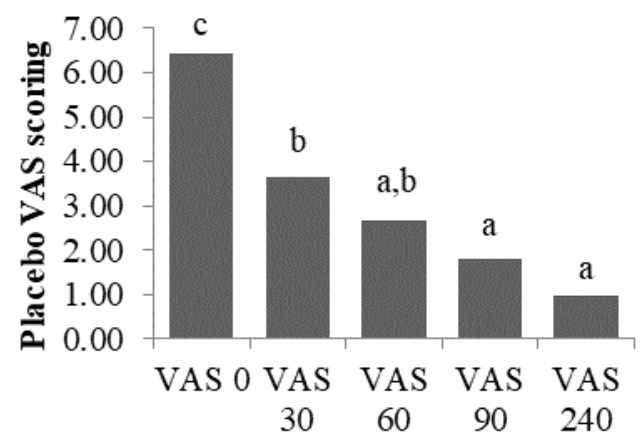

Figure 4: Effect of placebo on VAS scores in patients with $\mathrm{CO}$ poisoning. Test: Kruskall Wallis. Bars with different letters differ significantly $(p<0.05)$; bars with the same alphabets do not differ significantly

Trop J Pharm Res, October 2019; 18(10):2206 
It is apparent from these results that analgesics and placebo significantly reduced VAS scores in patients with $\mathrm{CO}$ poisoning. Therefore, differences among these four treatment groups at the same times of VAS scoring were analysed. As shown in Table 2 and Figure 5, at all-time points, there were no statistically significant differences amongst the groups ( $p>0.05)$. Values of VAS (0-240) were comparable amongst the four treatments.

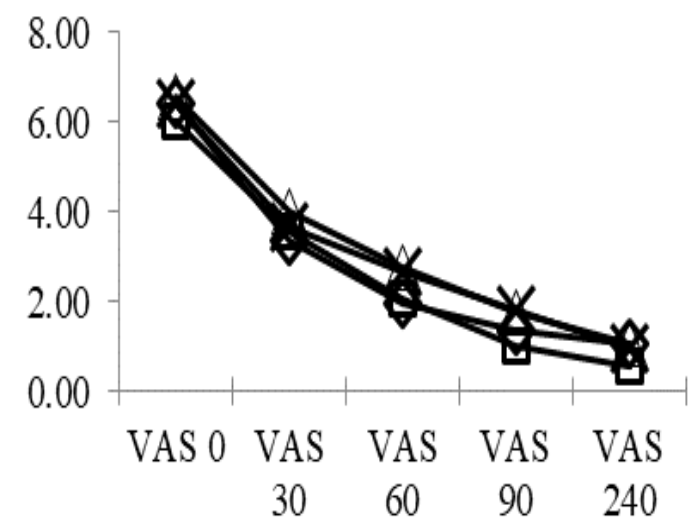

Figure 5: Effect of analgesics and placebo on VAS score in patients with $C O$ poisoning. $\Delta$ : Paracetamol; $\mathrm{X}$ : Placebo; $\diamond$ : Dexketoprofen; $\square$ : Ibuprofen

Finally, the patient's response to treatment and need for life-saving medicine after the treatment was evaluated. The results are shown in Table 3. There were no side effects in patients during the treatment.

\section{DISCUSSION}

This study has shown from VAS scores that the three different analgesics adequately reduced headache and pain in patients with $\mathrm{CO}$ poisoning when combined with oxygen therapy. However, the VAS score in the placebo group revealed a significant decrease in pain. Indeed, the three different analgesics and placebo (normal saline) had the same effect on VAS (0-240) scores: there were no statistically significant differences amongst them. Thus, the analgesics used for preventing headaches in $\mathrm{CO}$ poisoning are not superior to oxygen therapy. Exposure to $\mathrm{CO}$ is one of the leading causes of poisoning and is responsible for half of poisoning-related deaths world-wide [11,12]. Symptoms of CO poisoning are non-specific. The patients may be asymptomatic, or may exhibit a wide range of symptoms ranging from simple symptoms such as headache and nausea to more serious symptoms which may result in death [12]. The degree of clinical symptoms varies depending on the $\mathrm{CO}$ concentration to which the patient was exposed, the duration of exposure, and medical history [6]. The brain and central nervous system which have the highest oxygen needs and the highest metabolic activities, are the organs most affected by the toxic effects of $\mathrm{CO}$ poisoning [13]. Several hypotheses have been proposed to explain damaging effect of $\mathrm{CO}$ on the brain. General reduction of oxygen transport as a result of $\mathrm{COHb}$ formation plays an important role in CO-related brain damage [14].

Table 2: Comparative effect of analgesics and placebo on VAS scores (mean \pm SD)

\begin{tabular}{lcccccc}
\hline Parameter & \multicolumn{3}{c}{ Analgesic treatment } & Chi-square & \multirow{2}{*}{-value } \\
& Dexketoprofen & Ibuprofen & Paracetamol & Placebo & test value & \\
\hline VAS 0 & $6.43 \pm 2.05$ & $6.00 \pm 1.79$ & $6.55 \pm 2.23$ & $6.43 \pm 2.05$ & 1.29 & $\mathbf{0 . 7 3}$ \\
VAS 30 & $3.36 \pm 2.48$ & $3.55 \pm 2.25$ & $4.02 \pm 2.63$ & $3.64 \pm 2.98$ & 1.41 & $\mathbf{0 . 7 0}$ \\
VAS 60 & $1.95 \pm 2.42$ & $2.05 \pm 2.27$ & $2.76 \pm 2.44$ & $2.67 \pm 3.11$ & 3.98 & $\mathbf{0 . 2 6}$ \\
VAS 90 & $1.38 \pm 2.27$ & $1.02 \pm 1.63$ & $1.79 \pm 2.01$ & $1.81 \pm 2.44$ & 4.91 & $\mathbf{1 . 1 8}$ \\
VAS 240 & $1.07 \pm 2.19$ & $0.57 \pm 1.17$ & $1.07 \pm 1.88$ & $0.95 \pm 1.87$ & 0.61 & $\mathbf{0 . 8 9}$
\end{tabular}

Kruskall Wallis test, $p<0.05$

Table 3: Comparative effects of analgesics and placebo on treatment outcome

\begin{tabular}{|c|c|c|c|c|c|c|c|}
\hline \multirow[t]{2}{*}{ Variable } & & \multicolumn{4}{|c|}{ Analgesic treatment } & \multirow{2}{*}{$\begin{array}{l}\text { Chi- } \\
\text { square } \\
\text { test } \\
\text { value }\end{array}$} & \multirow[b]{2}{*}{$P$-value } \\
\hline & & $\begin{array}{c}\text { Dexketoprofen } \\
n(\%)\end{array}$ & $\begin{array}{c}\text { Ibuprofen } \\
\text { n (\%) }\end{array}$ & $\begin{array}{c}\text { Paracetamol } \\
n(\%)\end{array}$ & $\begin{array}{c}\text { Placebo } \\
n(\%)\end{array}$ & & \\
\hline \multirow{4}{*}{$\begin{array}{l}\text { Response } \\
\text { to } \\
\text { treatment } \\
\text { Life- } \\
\text { saving } \\
\text { medicine }\end{array}$} & Nil & $7(16.7)$ & $2(4.8)$ & $7(16.7)$ & $6(14.3)$ & \multirow{2}{*}{3.557} & \multirow{2}{*}{0.313} \\
\hline & Yes & 35 (83.3) & $40(95.2)$ & 35 (83.3) & $36(85.7)$ & & \\
\hline & Nil & $38(90.5)$ & $40(95.2)$ & 39 (92.9) & 39 (92.9) & \multirow{2}{*}{0.718} & \multirow[b]{2}{*}{0.869} \\
\hline & Yes & $4(9.5)$ & $2(4.8)$ & $3(7.1)$ & $3(7.1)$ & & \\
\hline
\end{tabular}

Chi square test, $p<0.05$ 
Headache is the first and most common symptom of $\mathrm{CO}$ poisoning and its incidence is up to $90 \%[11,15]$. The recommended treatment protocols for $\mathrm{CO}$ poisoning include removal from the exposure zone, provision of supplementary oxygen and general supportive treatment $[15,16]$. The supportive treatment includes the use of analgesics if the patient complains of headache. The exact mechanism involved in the development of headache after acute $\mathrm{CO}$ exposure is not fully understood [17]. As a result of clinical studies, hyperbaric and normobaric oxygen therapy have been shown to prevent many types of headache, especially migraine [18-20]. Oxygen inhibits the cranial parasympathetic vasodilator pathway, leading to cerebral vasoconstriction [20]. It also contributes directly to cerebral vasoconstriction, thereby potentially affecting the peripheral effects of catecholamines and serotonin [22]. However, it is not certain if this is the basis of CO-induced headache. It has been reported that patients who received only normobaric oxygen before HBOT had $72 \%$ reduction in headache. In the study, only $21 \%$ of patients were completely relieved of pain [23]. Based on this, it was felt that appropriate analgesic support for patients with headache due to $\mathrm{CO}$ intoxication would increase patient comfort.

NSAIDs are generally preferred for controlling emergency headache [24]. However, the drug of choice for headache may vary, depending on underlying causes [24]. In this study, there were significant decreases in VAS scores between 0 and $240 \mathrm{~min}$ in all treatment groups, including placebo. However, the only significant decreases in VAS score between 30 and 60 min were in the ibuprofen group. Thus, ibuprofen may be preferred for those who want early analgesic support within the first $60 \mathrm{~min}$. The present study is the first to show the efficacy of analgesia in the treatment of headache caused by $\mathrm{CO}$ intoxication. Decreases were seen in VAS (0240) values in the placebo and oxygen group, similar to a previous report [25]. Oxygen exerts therapeutic properties by reducing the half-life of CO. The decreases in VAS (0-240) values with time may be due to elimination of $\mathrm{CO}$ from the body.

\section{Limitations of the study}

One major limitation in this study is the small number of patients used. In addition, some of the $\mathrm{CO}$ poisoning patients might be chronic intoxication cases, in which case the chronic poisoning may have affected the response to analgesia. The causes of $\mathrm{CO}$ intoxication might also have affected the severity of pain and the response to treatment.

\section{CONCLUSION}

The results of this study suggest that medication and oxygen therapy produce the same effects when used in the treatment of headache caused by $\mathrm{CO}$ poisoning. Oxygen therapy alone reduces $\mathrm{CO}$ intoxication-induced headache. The results also show that ibuprofen is the most suitable analgesic for the treatment of acute pain in $\mathrm{CO}$ intoxicated patients.

\section{DECLARATIONS}

\section{Acknowledgement}

The author would like to thank Prof Dr Zeynep Çakır for support.

\section{Conflict of interest}

No conflict of interest is associated with this work.

\section{Contribution of authors}

We declare that this work was done by the authors named in this article and all liabilities pertaining to claims relating to the content of this article will be borne by the authors.

\section{Open Access}

This is an Open Access article that uses a funding model which does not charge readers or their institutions for access and distributed under the terms of the Creative Commons Attribution License (http://creativecommons.org/licenses/by/ 4.0) and the Budapest Open Access Initiative (http://www.budapestopenaccessinitiative.org/rea d), which permit unrestricted use, distribution, and reproduction in any medium, provided the original work is properly credited.

\section{REFERENCES}

1. Kao LW, Nañagas KA. Carbon monoxide poisoning. Emerg Med Clin North Am. 2004; 22: 985-1018.

2. Piantadosi CA. Carbon monoxide poisoning. New Engl J Med. 2002; 347(14): 1054-1055.

3. Sever H II, Avsaroğulları L, Sozuer ME, Ozkan S, Yurumez $Y$, Yavuz $Y$. Carbon monoxide poisoning in patients receiving emergency services with nonspecific symptoms. Turk J Emerg Med. 2005; 5(1): 18-21. 
4. Hampson NB. U.S. mortality due to carbon monoxide poisoning, 1999-2014. Accidental and intentional deaths. Ann Am Thorac Soc. 2016; 13(10): 1768-1774.

5. Tintinalli JE, Stapczynki JS. Emergency Medicine: $A$ Comprehensive Study Guide. 7th edn, New York: McGraw-Hill; 2011.

6. Sykes OT, Walker E. The neurotoxicology of carbon monoxide - Historical perspective and review. Cortex; a journal devoted to the study of the nervous system and behavior. 2016; 74: 440-448.

7. Eberhardt M, Powell A, Bonfante G, Rupp V, Guarnaccia $J R$, Heller M, Reed J. Noninvasive measurement of carbon monoxide levels in ED patients with headache. $J$ Med Toxicol. 2006; 2: 89-92.

8. Turner M, Hamilton-Farrell MR, Clark RJ. Carbon monoxide poisoning: an update. J Accid Emerg Med. 1999; 16(2): 92-96.

9. Burkhart JE Jr, Stoller JK. Oxygen and aerosolized drug delivery: matching the device to the patient. Clev Clin J Med. 1998; 65(4): 200-208.

10. International Ethical Guidelines for Health-related Research Involving Humans, Fourth Edition. Geneva. Council for International Organizations of Medical Sciences (CIOMS); 2016.

11. McMillan-Persaud B, Omole F, Clark K, Francois J. Headache, fatigue, blurred vision, Dx? J Fam Pract. 2015; 64(4): 228-230.

12. Roth $D$, Mayer J, Schreiber W, Herkner H, Laggner AN. Acute carbon monoxide poisoning treatment by noninvasive CPAP-ventilation, and by reservoir face mask: Two simultaneous cases. Am J Emerg Med. 2018; 36(9): 1718 e5-e6.

13. Karaman D, Metin S, Kara K, Ozdemir A, Yildiz S, Durukan I, Almbaidheen M, Uzun G, Turkbay $T$. Neuropsychological evaluation of children and adolescents with acute carbon monoxide poisoning. Pediatr Emerg Care. 2016; 32(5): 303-306.

14. Liao WC, Cheng WC, Wu BR, Chen WC, Chen CY, Chen $\mathrm{CH}$, Tu CY, Hsia TC. Outcome and prognostic factors of patients treated in the intensive care unit for carbon monoxide poisoning. J Formos Med Assoc. 2019; 118 : 821-827.
15. Zorbalar N, Yesilaras M, Aksay E. Carbon monoxide poisoning in patients presenting to the emergency department with a headache in winter months. Emerg Med J. 2014; 31(e1): e66-70.

16. Lin $\mathrm{CH}$, Su WH, Chen YC, Feng PH, Shen WC, Ong JR, Wu MY, Wong CS. Treatment with normobaric or hyperbaric oxygen and its effect on neuropsychometric dysfunction after carbon monoxide poisoning: $A$ systematic review and meta-analysis of randomized controlled trials. Medicine. 2018; 97(39): e12456.

17. Weaver LK. Clinical practice. Carbon monoxide poisoning. New Engl J Med. 2009; 360(12): 1217-1225.

18. Kudrow L. Response of cluster headache attacks to oxygen inhalation. Headache. 1981; 21(1): 1-4.

19. Ozkurt B, Cinar O, Cevik E, Acar AY, Arslan D, Eyi EY, Jay L, Yamanel L, Madsen T. Efficacy of high-flow oxygen therapy in all types of headache: a prospective, randomized, placebo-controlled trial. Am J Emerg Med. 2012; 30(9): 1760-1764.

20. Singhal AB, Maas MB, Goldstein JN, Mills BB, Chen DW, Ayata C, Kacmarek RM, Topcuoglu MA. High-flow oxygen therapy for treatment of acute migraine: $A$ randomized crossover trial. Cephalalgia. 2017; 37: 730736.

21. Akerman S, Holland PR, Lasalandra MP, Goadsby PJ. Oxygen inhibits neuronal activation in the trigeminocervical complex after stimulation of trigeminal autonomic reflex, but not during direct dural activation of trigeminal afferents. Headache. 2009; 49(8): 1131-1143.

22. Sakai F, Meyer JS. Abnormal cerebrovascular reactivity in patients with migraine and cluster headache. Headache. 1979; 19(5): 257-266.

23. Hampson NB, Hampson LA. Characteristics of headache associated with acute carbon monoxide poisoning. Headache. 2002; 42(3): 220-223.

24. Trainor A, Miner J. Pain treatment and relief among patients with primary headache subtypes in the ED. Am J Emerg Med. 2008; 26(9): 1029-1034.

25. Ocak T, Tekin E, Basturk M, Duran A, Serinken M, Emet $M$. Treatment in carbon monoxide poisoning patients with headache: A prospective, multicenter, double-blind, controlled clinical trial. Am J Emerg Med. 2016; 34(11): 2140-2145. 